\title{
THE SELECTION OF AN ENTRY MODE STRATEGY INTO FOREIGN MARKETS UNDER CONDITIONS OF ENVIR ONME NTAL UNCERTAINTY; A new approach to the market analysis using a spreadsheet to process quantitative fuzzy data
}

\author{
E. López, J. R. Mieres, \\ C. Mendaña, M. A. Rodríguez
}

The purpose of this paper is to offer managers an innovative and efficient methodology of analysis by which they can gain a more realistic perception of the environment. Hence decision making related to the selection of entry strategies will be done based on more reliable information.
In order to achieve this objective, the authors consider it is relevant to set this model of analysis within the background of the internationalisation process. A practical case of study is included to demonstrate the major advantages of this model.

\section{INTRODUCTION}

In recent years there has been a resurgence of issues concerning international trade. Several international developments have contributed to change the perception of international trade.

The creation of international regional economic integration agreements, such as NAFTA, MERCOSUR, European Union, etc., which attempt to promote and protect regional trade, has been one of the factors that affected the traditional perception of international business.

The General Agreement on Tariffs and Trade (GATT) can be considered as another one of the mile stones responsible for the change of this perception. While in the past most of the international markets remained protected by some kind of trade barriers, nowadays the international community seems to have agreed to an arrangement directed to the substantial reduction of tariffs and other barriers enhancing therefore, the elimination of discriminatory policies in the markets. 
In today's environment, there are more companies than ever engaged in international trade. Trading figures reflect this trend. According to Peattie $\mathrm{K} .{ }^{1}$, for much of the 1980s international trade was growing at a 15 per cent per annum, from around $\$ 2$ trillion in 1980 to over $\$ 5$ trillion by the end of the decade.

World trade has given rise to global linkages of markets, technology, and living standards that were previously unknown and unanticipated ${ }^{2}$. In consequence, competition seems to have acquired a new dimension within the international reality.

The new horizons opened in international markets offer endless opportunities for international expansion as well as endless threats to local companies. This is having a repercussion in, companies which are increasingly looking at the different entry methods used to enter international markets.

In order to give an integrated and analytical understanding of the use of these methods, it is important to identify and collect detailed information on the various issues that surround the internationalisation process and the various types of entry methods.

Furthermore, in an attempt to identify the implications that the theoretical evidence has on date to date business, the authors provide a detailed case study of a company which is involved in the selection process of an international entry strategy.

\section{THE INTERNATIONALISATION PROCESS: THE CONCEPT}

There are many ways of describing the methods employed by companies to penetrate international markets. Literature reviewed reveals that academics and companies use different terms to define foreign market servicing strategies.

Sometimes the term internationalisation only refers to entry strategies as such, focusing on entry only. Other times it involves long term international business relationships which include both, entry and subsequent market development.

However, the most common use of the term is that one described by Young et al. ${ }^{3}$ as the developmental process of increasing involvement in international business. This also includes the whole range of forms of undertaking business across national frontiers.

' Peattie, K., 1992.

2 C zinkota, M.and Ftonkainen, I A, 1993.

3 Young, S.; Hamill, J.; Wheeler, C. and Davies, J .R., 1989. 
Within the internationalisation process, several theories have been used to explain the process through which foreign market expansion takes place. Out of all of them, the stages theory of internationalisation has become the most widely accepted approach.

\subsection{THE STAGES THEORY}

The stages theory argues that firms proceed in a consistent stepwise fashion along some organisational continuum as they develop their international activities $^{4}$.

Yet, within the stages approach there are different perceptions as to how and why companies internationalise. For example, Wind and Perlmutter ${ }^{5}$ perceive internationalisation as a process in which specific attitudes are associated with successive stages in the evolution of international operations. They identify four attitude types which are: ethnocentrism, polycentrism, regiocentrism and geocentrism. These stages go from a perception where overseas operations are seen as secondary to domestic ones, to the stage where foreign involvement is reached and policies are developed on an international basis.

Other authors conceptualise internationalisation differently. Johannson and Vahlne $^{6}$ point out the importance of the link between resource commitment, export dependency and export organisation. They stress that firms have direct experience of resource influencing factors and this experience has a clear effect on establishing direct production facilities which is the final stage of foreign involvement.

Cunningham and Spigel $^{7}$ also support this idea. They understand that internationalisation "is a continuous process of choice between policies which differ maybe only marginally from the statusquo.... In terms of the learning curve theory, certain stimuli induce a firm to move to a higher export stage, the experience that is gained then alters the firm's perceptions, expectations and indeed managerial capacity and competence; and new stimuli then induce the firm to move to the next higher export stage, and so on".

Looking at these interpretations of the stages theory, it can be appreciated that firms involved in the process of internationalisation go through an orderly process in which they gradually gain experience. As experience is gained, it is quite likely that they can leam to reduce uncertainty and therefore to retain control over risk.

4 Tumbul, P.W., 1987.

5 Wind, Y. and Perimutter, H., 1977.

6 Johannson, J. and Vahlne, J.E., 1992.

${ }^{7}$ Cunningham, M.T. and Spigel, RJ ., 1987. 
Phillips, Doole and Lowe $^{8}$ suggest that firms approach international involvement cautiously. They found that for small and medium sized companies exporting seems to be the most promising alternative since it appears to offer a degree of control over risk cost and resource commitment

In their interpretation of the stages theory they understand that there are six stages of internationalisation.

1- Management is not interested in exporting and would be unwilling to fulfil an unsolicited order.

2- Management fulfils unsolicited orders from abroad.

3- Management explores the feasibility of exporting.

4- The firm exports to a familiar and close country.

5- The firm becomes an experienced exporter with sales being made to a number of overseas markets and representing a significant proportion of turnover.

6- Management explores exporting to distant countries and formulates a long term strategy for international markets.

In general, all the different interpretations of the stages theory have something in common with regard to the entry strategy. After unexpected international sales, companies became more interested in international markets and see exporting as the most appropriate strategy during the first stages of the internationalisation process.

\section{2. $\mathrm{Cr}$ it ic is $m$ to the stages theory}

In spite of the fact that the stages theory of internationalisation is widely accepted, some authors have tried to demonstrate that the popularity of the concept is not entirely consistent with some empirical and theoretical evidence.

Research on the internationalisation process done by Reid ${ }^{9}$ questions the fundamental validity of the stages approach. He criticises the theory's main assumption that firms develop more formal structures for handling export markets as they go through the different stages. Reid's view on internationalisation challenging the stages theory is overwhelming:

8 Phillips, E.; Doole, Y. and Lowe, $R_{n} 1994$.

' Reid, S., 1983. 
"Since exporting results from a choice among competing expansion strategies that are guided by the nature of the market opportunity, firm resources, and managerial philosophy, it represents a selective and dynamic adaptation to the changing character of the foreign market.... Market factors and requirements are therefore closely intertwined with deciding whether to go international and what form this expansion should take".

The implication of Reid's work is clear. When firms enter foreign markets, they do not necessarily have to follow any consistent approach dictated by the stages theory of internationalisation. The selection of market entry strategies must be done on the grounds of market factors and company considerations.

However, this interpretation of the internationalisation process seems to be based on assumptions that mainly affect large companies. These may have the resources and managerial philosophy needed to plan expansion strategies that do not necessarily follow any strategy developed from previous experiences.

Looking at the internationalisation process overall, one could understand that firms in general, need to go through a process of adaptation to the different stages. Each of these stages brings the companies the necessary experience and confidence to take advantage of new opportunities and, with it the possibility to pass to the next stage.

\section{THE MARKET ENTRY STRATEGY}

Once a firm is well on its way to becoming internationalised, the selection of the entry mode used to penetrate a foreign market should be done considering the methods that are consistent with the strategic objectives of the firm, its resource capability and the stage in which the firm is In the internationalisation process.

Nevertheless, before the factors that influence the entry mode are analysed in depth, it is necessary to understand what is meant by the entry mode.

3.1. Entry mode. Definition

It is generally understood that an entry mode is an institutional agreement which will be necessary for the entry of a company's products, technology, and human and financial capital into a foreign market.

Root ${ }^{10}$ sees the entry mode more specifically as a comprehensive plan which has into account the objectives, resources and policies that will guide the firm's international marketing operations over some future time period that is of sufficient length for the firm to achieve sustainable growth in foreign markets.

${ }^{10}$ Root, F.R., 1994. 
In relation to this, Roofs work underlines that the decision concerning what specific international marketing method to use is not a simple one. For many companies, the formulation of the entry strategy rather than being viewed as a simple plan, it will be the result of several individual product and market plans which are affected by a series of factors (section 5).

\section{ENTRY MODES}

In order to understand the importance and implications of each method, efforts are made to identify the distinctive characteristics and to differentiate them in terms of the risk and control that they carry.

The assessment of the methods is done by commencing with those which carry the least risk and progressing to the range of contractual modes such as direct investment production modes. Please note that, given the objective of this paper, the following section does not attempt to incur in a deep analysis of everyone of the different entry modes.

\subsection{Exporting}

Exporting is generally classified as being the method with the least risk. There are two basic forms: indirect and direct exporting. They can be distinguished on the basis of how the expor-ting firm carries out the transactions flow between itself and the importer or foreign buyer.

\subsubsection{Indirect Exporting}

A firm is an indirect exporter when its products are sold in foreign markets without any special activity for this purpose being undertaken within the company. The export operations, including all documentation, physical movement of goods and channels of distribution for sale are carried out by others and this activity may even take place without the knowledge of the manufacturer ${ }^{11}$.

Throughout international markets there can be many forms of indirect exporting. The most popular of these $\mathrm{e}^{12}$ are:

- - Home country based merchants:

Export Merchant

Trading Company

${ }^{11}$ Young, S.; Hamill, J ; Wheeler, C. and Davies, J .R., 1989.

${ }^{12}$ Albaum, G.; Strandskov, J .; Duerr, E. and Dowd, L, 1994. 
- Home country based agents:

Export Commission House

Export Management Company (EMC)

- Cooperative organisations:

Piggyback agreements

Exporting Combinations

- Home country based merchants:

Export Merchants: A domestic based export merchant buys and sells on its own account. All aspects of the international marketing task are handled by the merchant except when some changes are required to be made to the product.

Trading company: They generally engage in both exporting and importing. Although trading companies are common everywhere, it is in Japan where this concept has been applied most efficiently. The largest are commonly known as Sogo Shosha.

- Home country based agents:

There are several types of agents located in the country of export who are available to firms wishing to export.

Export Commission House. The export commission house is a representative of foreign buyers who resides in the exporter's home country. They are practically domestic buyers. From the exporter's point of view, this form of selling represent an easy way of export There is very little risk; however, the control that the exporter may have over the international marketing of products is practically non existent.

Export Management Company (EMC). Is a specialist company set up to act as the export department for a range of companies. The EMC conducts business in the name of each manufacturer it represents. It often takes over all the risks and problems of export and the manufacturer just fills the orders.

- Co-operative organisations:

There are basically two types of export organisations:

Piggyback agreements: A company sells its goods abroad through the overseas distribution facilities of another company. The two firms would normally have complementary, non competitive or unrelated products. 
Exporting Combinations: These are formal associations of independent and competitive business firms who's main priority is to sell to foreign markets. The most common type of export combination is a marketing co-operative association of producers.

\subsubsection{Direct Exporting}

A company is a direct exporter when it sells directly to an importer or a buyer located in a foreign market area. Implication of this type of exporting is that the company undertakes the export task itself, and therefore has to create and develop its own contacts, undertake market research, handle documentation, deal with the marketing mix and so on.

The most popular form of direct exporting are:

- Agents or Distributors

- Export Salesman

- Export Sales Subsidiary

Agents and Distributors: They are the most common form of low cost direct involvement in foreign markets. A major difference between these two is that, the distributor actually takes tittle of the goods and represents the exporting company in the sales and service of the products. The Agent is usually paid commission only on sales and it is not responsible for unsold products.

Export salesperson: Export salesperson is one who resides in one country, which depending on sales requirements of the products, will be the home country of the exporter or a resident in the foreign country.

Export Sales Subsidiary: When a company decides to have closer supervision over the sales made in a particular market area it can opt for establishing a foreign sales subsidiary. The foreign sales subsidiary handles all the sales, distribution and promotional work through a designated market area.

\subsection{Lic ensing}

The term licensing is used to refer to those contracts in which a foreign licensor provides a local licensee with access to a set of technologies or know-how, in exchange for financial compensation. Typically, the licensee would have the exclusive rights to produce and market a product with in an agreed area for a period of time. 


\subsection{Franchising}

Franchising is a particular type of licensing. It is a marketing-oriented method of selling a business service. In a franchising agreement the franchisor transfers the legal right to use a company's registered trade name, trademarks and logo, products, packaging and business system.

\subsection{For eign dir ect invest ment (FDI)}

These term is used to designate when a company engages in the process of starting production or manufacturing facilities within a foreign market to produce its current product line. FDI can take two different forms:

- Acquisition / Takeover of an existing firm

- Greenfield Subsidiary

\subsection{J o int venture}

A J oint Venture can be described in general terms as an arrangement involving the co-operative efforts and utilisation of the resources of two or more separate entities working together to accomplish agreed-upon goals. J oint Ventures are generally conducted through a separate entity that is established and owned by the group of entities participating in the joint venture relationship ${ }^{13}$.

\subsection{Strategic Alliances}

Strategic Alliances may involve virtually any of the international market entry modes but especially licensing and contractual equity joint ventures.

Alliances can be linked to $R \& D$ and technology and also marketing distribution agreements.

As seen from above, there is a wide variety of entry methods that can be used in the internationalisation process. Usually, the selection of a particular method will depend upon the degree of control that a firm wishes to have over certain factors i.e. the marketing mix strategy, geographic coverage, decision making, etc. This is likely to be linked to the stage in which the company is engaged in the internationalisation process. 


\section{FACTORS INFLUENCING THE ENTRY MODE}

A company's selection of the entry method is based on either or both of two approaches: Through experience or through analysis'4.

On the one hand, for many firms the formulation of the entry mode can be seen as an evolutionary process; therefore, firms can decide upon their own experience or that of other firms, that a particular entry strategy is desirable to introduce its products into a market.

On the other hand, an entry mode may be arrived at after making an analysis of the market and its major players; i.e.: needs and buying habits of potential customers, the competition, competence of marketing organisations, risk factors, etc.

This type of analysis can be carried out in two different forms. One of them is by using techniques capable of allowing the collection of data from that uncertain and dynamic reality that is the market. This provides companies with qualitative information which sometimes is subject to the subjectivism of the persons that use it. The other one uses techniques capable of identifying certain events that are formalised with the purpose of operating with them. This provides companies with quantitative information.

\subsection{Qual it at ive analys is}

Phillips, Doole and Lowe ${ }^{13}$ consider that there are four main categories of factors that influence the strategic development of the entry mode. These are: market and customer, geographical considerations, competition, company objectives and culture.

There are several approaches that can be used to structure an analysis of these factors. These are:

- SLEPT analysis which considers the study of the social, legal, economic, political, and technological factors. These methods give an appropriate focus of the market reality by evaluating and assessing the factors that might affect it.

- Porter's competitive analysis which provides a clear understanding of the mechanisms that link together the competitive environment given the complexity of the competitive forces. There are four key forces to be considered in this analysis:

${ }^{14}$ Albaum, G.; Strandskov, J .; Duerr, E. and Dowd, L, 1994.

${ }^{15}$ Phillips, E.; Doole, Y. and Lowe, FL, 1994. 
1. The power of suppliers

2. The power of customers

3. The threat of new entrants

4. The threat of substitutes

- Product Life Cycle, portfolio analysis, value chain analysis, and decision matrices that help to assess the different degrees of control over sales, the risk perception of certain attitudes, etc.

The idea of assessing all these factors, as J ohnson and Scholes ${ }^{16}$ put it, is to identify key elements that help to design the strategy that takes advantage of the opportunities that presents the new market and overcome the threats. At the same time it must also identify the aspects of the company's capability that provide strengths or indicate weaknesses in dealing with the new market.

\subsection{Quant it ative analysis}

To obtain reliable quantitative data in today's environment, where the uncertain ty of international markets is a well known fact, has become a key issue of special relevance for managers in their attempt to reduce risk.

Throughout the last decades, academics and businessmen have been using a wide variety of quantitative methods to evaluate the risk that companies will be taking when pursuing specific strategic options. These include financial ratio projections, sensitivity analysis, decision matrices, simulation modelling, Heuristic models, etc. These are generally based on economic studies that rely heavily on certainty and probability. But nevertheless they do not reflect the new dynamic of the environment.

The efficiency of these methods has been severely criticised on the grounds that the probability deals with a special kind of uncertainty which is objective (they refer to experiments which are not depending on the person that undertakes them). Furthermore, in dealing with economic data, it results very difficult to repeat a phenomenon enough number of times for the probability to be reliable ${ }^{17}$.

In consequence, some authors have suggested a change in the way data is collected and processed. The identification of data and its collection from the reality has traditionally taken place through reasoning based on the concept of precision. As a result, reality has been modified in order to be adapted to mathematical models when, ideally, the model should be adapted to the real facts.

${ }^{16}$ J ohnson, G and Scholes, K., 1989.

${ }^{17}$ López González, E. and Mendaña Cuervo, C., 1994. 
This indicates that, in order to get a more accurate view of reality, data should be handled without unnecessary transformation.

He proposes that the usage of Fuzzy numbers in the strategic decision making would seriously improve managers' perception of the market.

If the Knowledge of the market and its environment is imprecise, as it occurs in the taking of managerial decision, the mathematical tool used to assess it must include the notion of level of presumption ${ }^{10}$.

The usage of Fuzzy numbers accomplices that requisite. López-González, E. y Mendaña-Cuervo, $C$. stress that the usage of Fuzzy numbers in the decision making requires the incorporation of hypothesis that, even when they are not measurable, they are capable of estimation, comparison and gradation, relation etc. This is important because if a situation can not be specific but it can be stated that it is better that another one, we pass to a superior stage of knowledge and besides it can be use for a mathematical operations.

Following this kind of reasoning, Fuzzy numbers could be very well used to analyse the different alternatives that a firm has to enter new markets. Based on market analysis or, on the firm or other companies' previous experiences, (see section 1.4) a firm should be able to predict (with a wide or narrow marginal error) a series of variables; i.e.: fix and variable costs, sales, etc.

The results of this analysis can be used to produce a graphic picture in which the entry strategy is plotted against a certain level of presumption. Managers can therefore, make comparisons between different strategies and choose the entry mode that best suits their firm.

Despite of the fact that quantitative methods provide very reliable information, managers should not take the decision of using a particular entry mode just on this grounds.

Quantitative and qualitative methods complement each other and therefore, the combination of the two of them give a much clearer perception of the reality that surrounds the entry into an unknown market.

To obtain a practical view of the quantitative analysis, which is one of the objectives of this paper, the next section deals with a real case of study in which a Spanish company implements this type of market analysis. 


\section{CASE STUDY}

\subsection{Prada a TopeS. A. Company prof il e}

Prada a Tope is a family owned company stabilised in 1971 . O riginally it started as a small shop managed by J osé Luis Prada in Cacabelos, little village situated in the region of "EI Bierzo", province of León (Spain). A few years after its formation, Prada started to explore new commercial opportunities. With determination, courage and a strong drive towards success, Prada managed to open another shop, a restaurant and manufacturing facilities in which he produces and sells a wide range of regional products i.e. peppers, wine and liquors, cherries, pears, and chestnuts in syrup, honey, etc.

Today Prada S.A. has become a company that has an average of 45 employees throughout the year and a turn over of more than Pts 300 million a year.

The company is currently divided in two business units. One of them deals with specialised retail outlets undertaking all the marketing activities related to the selling of the company's products to a number of private companies and shops through out Spain. The other one co-ordinates the marketing activities and relationships with franchisees through out $\mathrm{S}$ pain.

Since 1990 the company has been engaged in a process of expansion through out Spain. Now the business counts with 11 franchisees partners, 7 shops and 4 restaurants.

In the period 1990-1991 a number of European companies visited Prada in order to import their products into their national markets. Prada's management at the time did not see it appropriate to start exporting. The process of expansion through out Spain, which required undivided attention and, perhaps the fear to engage in complicated and unknown business activities stopped the company going international.

Although Prada's management did not react then to the international challenge, in 1994 the company received again another unsolicited order. This time from Mexico. Despite Mexico is far more distant from Spain than any of the European countries, cultural similarities, language, psychological closeness, and maybe the fear of letting go pass another opportunity, was the trigger for the first international experience.

In 1995 the company has consolidated its position within the Spanish market and therefore, $\mathrm{Prada}$ is facing a new stage of development. Several factors such as the current dismantle of international trade barriers, specially in Europe, competitive pressure, market saturation, local incentives and so on, are contributing to boost the willingness to go internationally. 
In consequence, Prada's management has spent the last few months identifying ideal markets for their products within Europe. Recently, several Chambers of Commerce has been contacted to seek guidance in the international venture.

After some consideration of Prada's management capability and products, experts from the Chamber of Commerce suggested two European countries, Great Britain and Germany, as the most appropriate ones to market their products. Finally, after further consultation with the Embassies of the two countries, the company decided that the UK market was the one that best suits the company objectives.

In this respect, Prada's management has earned out a market research study in order to identify an entry mode strategy which positions the company within the British market.

Three different entry methods -agent distributor, export merchant and sales person- have been considered as the most appropriate strategies that Prada should use given its current situation in the early stages of the internationalisation process, the risk management is prepared to take, and the company capabilities and culture.

\subsection{Interpretation of the quantit at ive analysis}

A wide range of data has been gathered from different sources in order to accomplish this analysis. Some of it is accurate information taken from the market place i.e. current prices for services and goods. The rest has been collected from the opinion of the experts that the authors interviewed. Several variables have been used to analyse the alternatives.

All the information however, contains certain degree of uncertainty which is reflected in a degree of confidence or presumption.

In order to measure this uncertainty and operate with it without any transformation, it was considered that the use of Fuzzy numbers would be the most appropriate tool of assessment.

The information collected has been input in the spread sheet included in Table 1 in Appendix which operates according to the Fuzzy Subset theory and rules (Formulation is included).

This spreadsheet allows the comparison of the three alternatives based on a number of variables which are listed in the next section. 


\subsection{Assessment $\mathrm{Cr}$ iteria}

First of all, it is important to know that comparisons of the three entry modes are made on predictions for the next five years.

The variables utilised are:

- Revenue: (for wine and pepper).

For the case of the wine, the revenue has been calculated considering the forecast of the experts, who have taken into account their own experience and market trends.

Three different values are reflected on every year (see spreadsheet in Appendix). The middle one corresponds to the forecast given by the experts. The other two are calculated considering certain marginal error. Sales predictions are never accurate figures. There are many factors that affect it and therefore, it is necessary to consider the marginal error.

In this case the Sales Person Revenue for wine in the first year considers a marginal error of 0.07 (7 per cent) -pessimistic prediction- which means that the original revenue prediction $(160,000)$ might be decreased by 7 percent $(148,800)$.

In the second and following years, the forecast given might only decrease by 6 per cent, which is the left figure of the other years.

The reason why the marginal error varies with the years is because during the first year Prada has to create its own consumer demand. However, During the next years if the company implements a sound marketing policy, not only sales will increase, but also the accuracy of prediction since the forecast will be based on a consumption pattern that already exists.

Notice that this will be different with the other two alternatives. Export Merchant and Agent Distributor only count with a pessimistic prediction of 5 per cent (0.05) marginal error during the first year. This is because these two already have their distribution network and their own market. Therefore, it would be easier for them to introduce the wine in the market. For the rest of the years the three alternatives will be in the same conditions. They will all count with a 6 per cent pessimistic marginal error.

The figure on the right hand side for the Sales Person Revenue for wine (0.02) represents an optimistic marginal error of 8 per cent $(163,200)$ in the first year and the same percentage of marginal error is applicable for the second year. 
However during the third year, according to the opinion of the experts, Prada would have to expand and have more than one Sales Person. Sales should increase as a result and therefore, a 6 per cent optimistic marginal error is applied.

Once Prada's brand is established in the market (do not forget that the consumption of still wine is declining), the revenue figure can not be very optimistic. This is why only 1 per cent in the fourth year and 2 per cent in the fifth have been used.

The revenue for peppers is affected by different factors. The fact that it is an innovative product in the groceries market implies that the forecast will possess a higher degree of uncertainty. The three entry modes will have to cope with this situation. Predictions for all the years must reflect it. Therefore, they all have an 8 per cent of pessimistic marginal error meaning that the revenue might be smaller that predicted.

Given the nature of the product, its acceptance might also be bigger than the expected revenue forecast. Hence, a 3 per cent marginal error has been considered for every alternative.

- Expenses:

This variable includes the cost of a variety of elements such as company car, office, costs of transport of goods, telephone and marketing expenses etc. They are calculated on yearly bases.

The calculation of the value for Sales person has been done taking as reference current prices at the market place. This figure is therefore relatively accurate but it still contains certain degree of uncertainty. It has an optimistic marginal error of 3 per cent and a pessimistic of 1 per cent on every year.

For the Agent Distributor and Export Merchant, the certainty of predictions varies a bit. Prada would not have control over all the expenses because some of them will depend on the conditions of the contract with the Export Merchant and the Agent Distributor. Therefore, it has been considered a pessimistic marginal error of 3 percent $(0.03)$.

Operating with the variables defined above, will allow managers to obtain a range of different results that are analysed and compared in order to select the most appropriate one.

A traditional point of view would show that the Agent distributor is the alternative that provides the bigger Net Present Value; therefore the best option. This is due to the fact that traditional approach only works with exact 
values. In this case this is represented by the central value of each of the alternatives. As it can be seen in figure the central value and therefore the value used by the traditional techniques would be $1.220 .859,3$ for Sales Person, 1.246.910,9 for Agent Distributor and 1.237.854,4 for Export Merchant.

However, if we take into account that reliable forecast based on an exact perception of the data is rather difficult to achieve, it is convenient to include the central value within an interval (Fuzzy numbers). But in any case, the central value would still be the most expected one. In this way, traditional approach is greatly improved.

Hence the use of Fuzzy numbers facilitate not only the decision making on the grounds of the Net Present Value, but also gives us a perception of the strategy on the grounds of the environmental conditions which includes the most pessimist, the most realistic and the most optimistic perception of the uncertain future.

In this respect, thanks to the use of Fuzzy numbers, if the company is risk adverse and wants to avoid risks at any cost, the most appropriate entry method would be the use an Export Merchant. The interval of each strategy is Sales Person 1.093.859,1 - 1.411.533,6; Agent Distributor 1.131.163,4 1.311.244,8; Export Merchant 1.198.874,6 - 1.265.876,4. See Table 2 (in Appendix).

On the other hand, despite the fact that Sales Person is the riskiest alternative, given good environmental conditions, it will be the one that provides the company with the greatest Net Present Value. This is due to the fact that the centroid of the Sales Person is bigger than the other two. (Sales Person 1.236.786,8; Agent Distributor 1.234.057,5; Export Merchant 1.235.114,9). See Table 2.

\section{CONCLUSION}

In today's international environment competition seems to have acquired a new dimension. Managers, more than ever before, feel the need to develop methods of environmental analysis that can provide a more realistic perception of the environment in order to make accurate decisions. Current environmental monitoring techniques are becoming increasingly inefficient as the environment becomes more complex and dynamic.

In this account the authors intend to provide another point of view, based on the Fuzzy Subset theory, by which reliable information can be obtained from the environment and processed, in a precise manner, with the use of spreadsheets. 
It is particularly in the selection of international entry strategies where an appropriate environmental analysis is essential and where the use of Fuzzy quantitative techniques can be very valuable.

The criteria for selecting the right international entry strategy is not a simple and straight forward process. It is rather difficult to find a particular entry mode that fully satisfies a company.

Firms should consider all alternative entry modes, find a balance and select the best entry method. This will be one which is situationally best, optimal in that it is often a satisfying strategy in relation to the risk the management is prepared to take, the company's policy and its capability and culture.

A number of entry methods have been considered in this study; however, for the purpose of this paper, the authors have considered appropriate to explain in full detail only those entry methods that are suitable for the company being used in the case study. In this sense, the early stages of the internationalisation process in which Prada A Tope S.A. is, suggest that any of the different forms of exporting would be the most appropriate methods, particularly agents distributors, export merchant and sales person given the company's capabilities, policy and culture. Nevertheless, a brief reference to the rest of the entry methods is given in order to provide a wider view of the issue being researched.

The economic implications of these three entry methods for Prada A Tope, S.A. are analysed and compared using a spreadsheet that operates according to the Fuzzy theory. This analysis provides the managers with a higher degree of knowledge about the environment than that provided by traditional quantitative and qualitative methods of analysis.

It is the intention of the authors not to diminish the value of other methods of environmental analysis, but to enhance the importance of using these methods in conjunction with Fuzzy techniques.

\section{REFERENCES}

Albaum, G.; Strandskov, J.; Duerr, E. and Dowd, L (1994). 'International Marketing and Export Management". Routledge.

Cavusgil, T. and New in, J.R. (1981). "Internal determinants of Export Marketing Behaviour: An Empirical Investigation". J ournal of Marketing Research, 28.

Cunningham, M.T. and Spigel, R.J. (1987). "A Study in successful exporting". European J ournal of Marketing.

Czinkota, M. and Ronkainen, I.A. (1993). 'International Marketing". The Dryden Press. United Kingdom. 
Johannson, J. and Vahıne, J.E. (1992). "The Mechanism of Internationalization". International Marketing Review, 7.

Johnson, G. and Scholes, K. (1989). Exploring Corporate Strategy. Prentice Hall.

Kaufmann, A. and Gil Aluja, J. (1986). Introducción de la Teoría de los Subconjuntos Borrosos a la gestión de las Empresas. Milladoiro. Santiago de Compostela.

Lopez Gonzal ez, E. and Mendaña Cuervo, C. (1994). "The outsourcing decision in Fuzzy Economic Environments". Proceedings International AMSE Symposium "Fuzzy Systems \& Neural Networks", Lyon (France), July 4-6, AMSE Press, p. 39-54.

Mor r is, J .M. (1987). J oint Ventures. J ohn Wiley \& Sons. New York.

Pauw oda, S. (1993). International Marketing. Butterworth-Heinemann Ltd.

Peat tie, K. (1992). Green Marketing. Pitman Publishing.

Phillips, E.; Doole, I. and Lowe, R. (1994). International Marketing Strategy. Analysis, Development and Implementation. R outledge.

Porter, M.E. (1980). "Competitive Strategy: Techniques for Analyzing Industries and Competitors". The Free Press.

Reid, S. (1983). "Export Research in a Crisis. In Export promotion. The Public and Private Sector Internationalization". M. Czinkota, New York, Praeger, p. $129-153$

Root, F.R. (1994). Entry Strategies for International Markets. Maxwell McMillan International, Canada.

Turnbul, P.W. (1987). A Challenge to the Stages Theory of Internationalisation process. Managing Export Entries of Expansion. Praeger, New York.

Wind, Y. and Perlmutter, H. (1977). "On identification of frontiers issues in international marketing". Columbia Journal of Worlel Business. United Kingdom.

Young, S.; Hamill, J.; Wheeler, C. and Davies, J.R. (1989). International Marked Entry and Development. Harvester Weatsheaf. United Kingdom. 
appendix

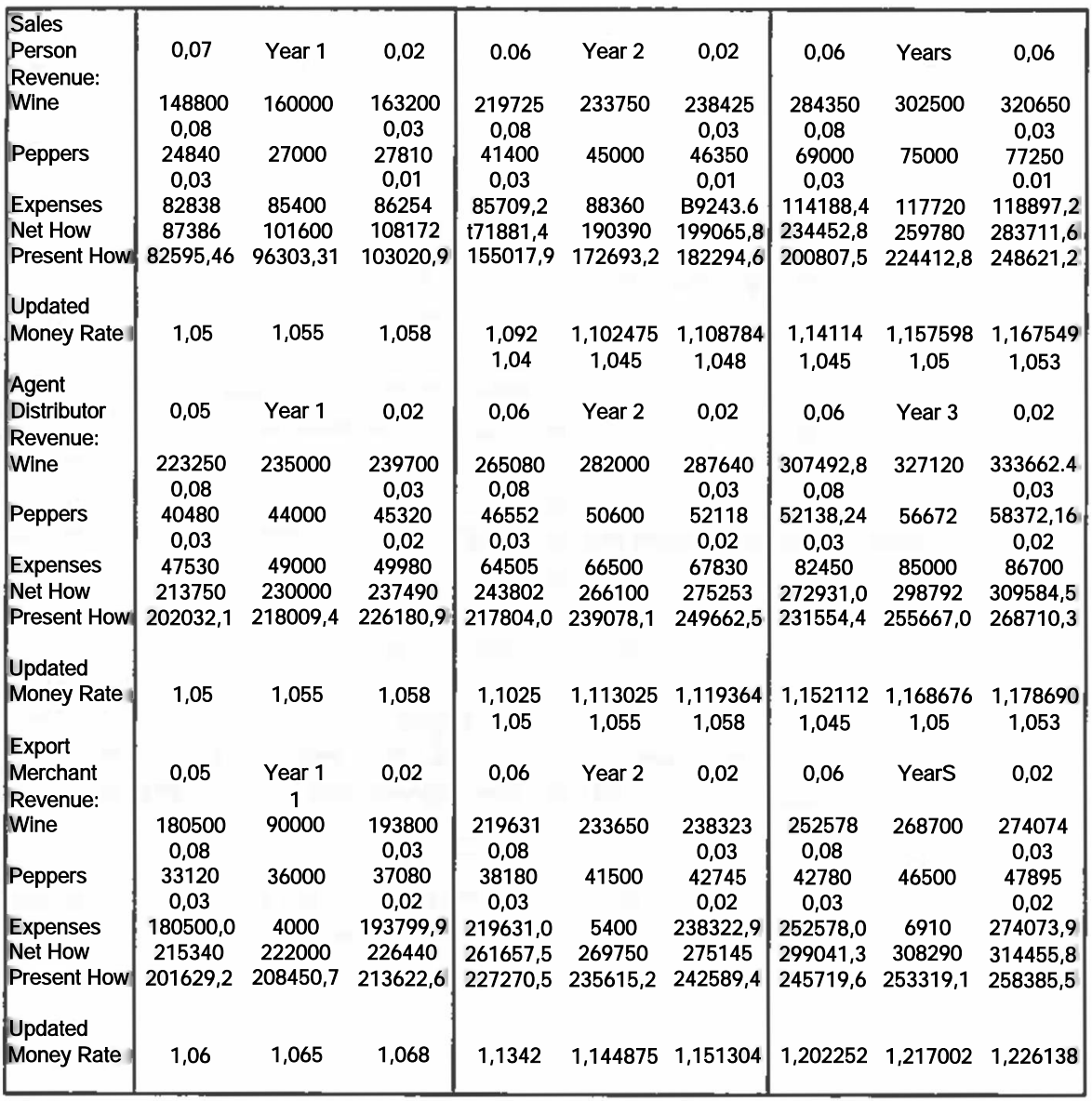

Table 1. Sales forecast for different entry strategies 


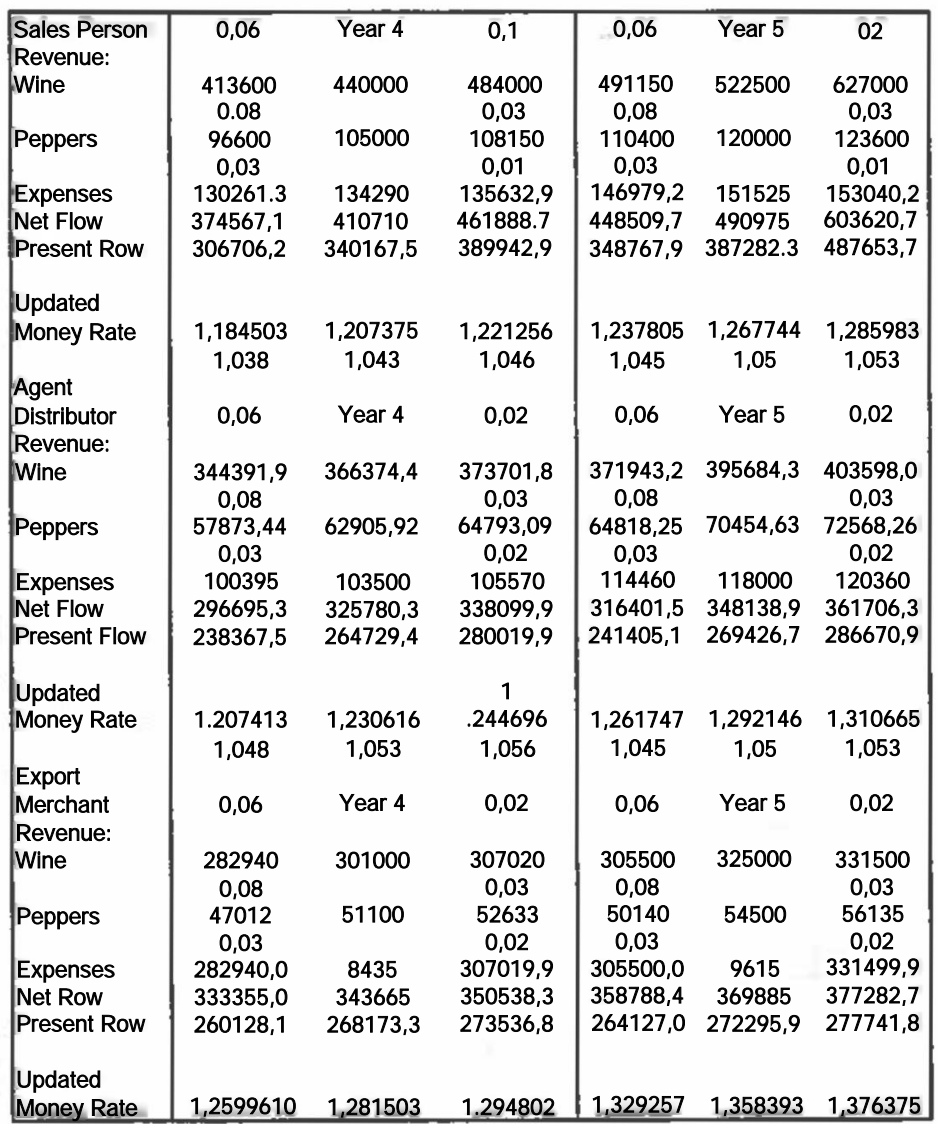

Table 1. Sales forecast for different entry strategies (continuation) 
Ths selection of an entry mode strategy into foreign markets under...

$\begin{array}{lccc}\text { Sales Person } & 1.093 .695 & 1220.859 & 1.411 .534 \\ \text { Centroid } & & 1236.787 & \\ \begin{array}{l}\text { Agent Distributor } \\ \text { Centroid }\end{array} & 1.131 .163 & 1246.911 & 1.311245 \\ & & 1.234 .058 & \\ \begin{array}{l}\text { Export Merchant } \\ \text { Centroid }\end{array} & 1.198 .875 & 1237.854 & 1265.876 \\ \end{array}$

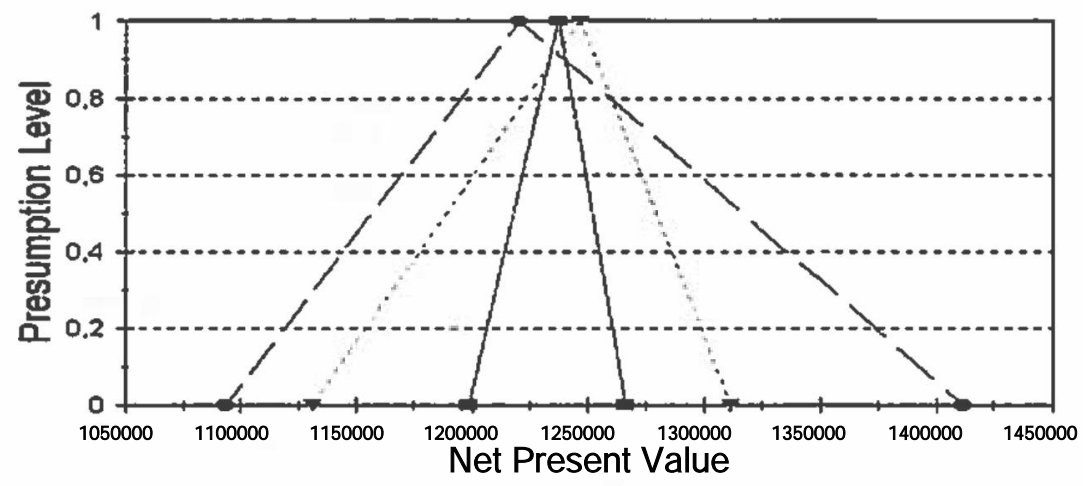

L- $\rightarrow$ Sales Person Agent Distributor- - - Export Merchant

Table 2. Net $\mathrm{P}$ resent $\mathrm{V}$ alue fu $\mathrm{H}$

\section{Formulation}

\begin{tabular}{|c|c|c|c|}
\hline & sales forecast for & & \\
\hline CASE ZA3: & $\begin{array}{l}\mathrm{s} \text { ales } t \text { or ecast } t \text { or } \\
\text { DIFFERENT ENTRY STRATEGIES }\end{array}$ & CASETPB: & Arears \\
\hline CASE :A6: & 'Sales Person & $\begin{array}{l}\text { CASE:Q6: } \\
\text { CASE:A7: }\end{array}$ & $\begin{array}{l}\mathbf{0 , 2} \\
\text { 'Revenue: }\end{array}$ \\
\hline CASE 1C6: & 0,07 & CASE:B7: & Wine \\
\hline CASE :D6: & AYear1 & CASE:C7: & $-C \$ 6 ' D 7+D 7$ \\
\hline CASE :E 6: & 0,02 & CASE :D7: & 160000 \\
\hline CASE :F6: & 0,06 & CASE:E 7: & +D7+E\$6*D7 \\
\hline CASE:G 6: & *Year2 & CASE:F7: & $-\mathrm{F} \$ 6 * \mathrm{G} \mathrm{7+G7}$ \\
\hline CASE :H6: & 0,02 & CASE:G7: & 233750 \\
\hline CASE :16: & 0,06 & CASE:H7: & +G 7+H\$6'G 7 \\
\hline CASE' 6: & AYear 3 & CASE:17: & $-W J \mathbf{J} 7 \mathbf{J} 7$ \\
\hline CASE:K6: & 0,06 & CASEJ 7: & 302500 \\
\hline CASE :L6: & 0,06 & CASE:K7: & $+\mathrm{J} 7+K \$ 6 * \mathrm{~J} 7$ \\
\hline CASE :M6: & & CASE:L7: & -L\$6'M7+M7 \\
\hline CASE :N6: & 0,1 & CASE:M7: & 440000 \\
\hline CASE:06: & 0,06 & CASE :N7: & $+M 7+N \$ 6 * M 7$ \\
\hline
\end{tabular}




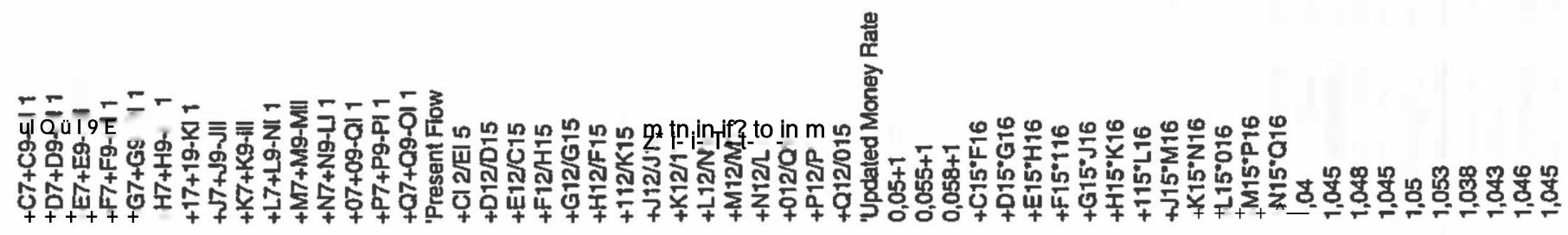

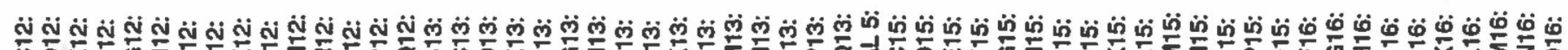

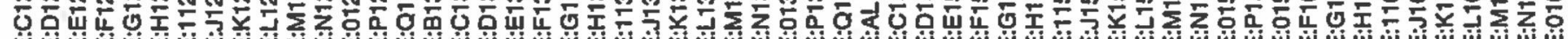

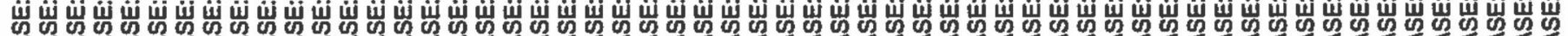

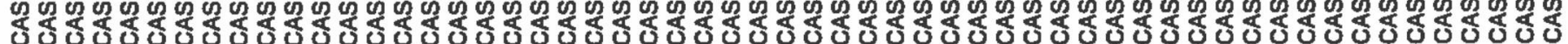

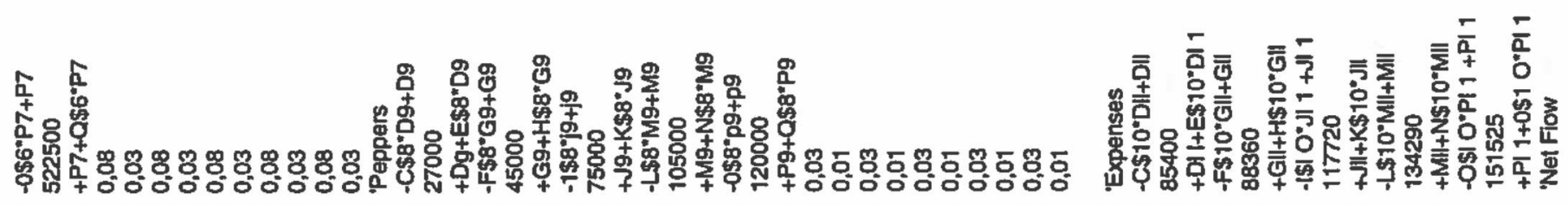

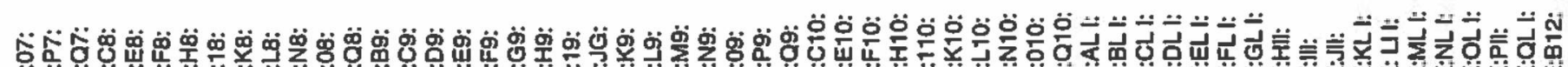

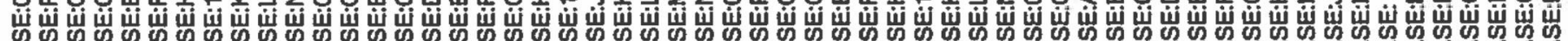

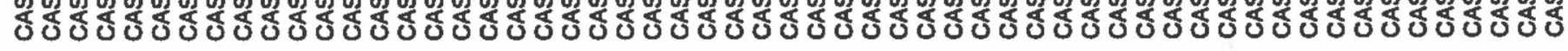




\begin{tabular}{|c|c|c|c|}
\hline CASE:P16: & 1,05 & CASE :N20: & $+\mathrm{M} 20+\mathrm{N} \$ 19 * \mathrm{M} 20$ \\
\hline CASE:Q16: & 1,053 & CASE :020: & $-0 \$ 19 * P 20+P 20$ \\
\hline CASE :A17: & 'Agent Distributor & CASE :P20: & $+\mathrm{M} 20+\mathrm{M} 20 * 0,12$ \\
\hline CASE:C17: & 0,05 & CASE:Q20: & +P20+Q\$19*P20 \\
\hline CASE :D17: & ryeart & CASE:C21: & 0,03 \\
\hline CASE:E 17: & 0,02 & CASE:E 21: & 0,02 \\
\hline CASE:F 17: & 0,06 & CASE:F21: & $+C 21$ \\
\hline CASE:G17: & ${ }^{A}$ Year2 & CASE:H21: & tE 21 \\
\hline CASE:H17: & 0,02 & CASE:121: & $+\mathbf{F} 21$ \\
\hline CASE 117: & 0,06 & CASE :K21: & +H21 \\
\hline CASEJ 17: & ${ }^{\text {AYear3 }}$ & CASE :L21: & +121 \\
\hline CASE:K17: & 0,02 & CASE :N21: & +K21 \\
\hline CASE :L17: & 0,06 & CASE :021: & $+\mathrm{L} 21$ \\
\hline CASE :M17: & AYear4 & CASE:Q21: & +N21 \\
\hline CASE :N17: & 0,02 & CASE 1B22: & 'Expenses \\
\hline CASE:017: & 0,06 & CASE:C22: & $-C \$ 21 ' D 22+D 22$ \\
\hline CASE :P17: & ${ }^{\text {AYear5 }}$ & CASE :D22: & 49000 \\
\hline CASE:Q17: & 0,02 & CASE:E 22: & +D22+E 52VD22 \\
\hline CASEtALS: & Revenue: & CASE:F22: & $-F \$ 21 * G 22+G 22$ \\
\hline CASE: BI 8: & Wine & CASE:G22: & 66500 \\
\hline CASE:C 18: & $-C \$ 17 * D 18+D 18$ & CASE:H22: & $+G 22+H S 21 * G 22$ \\
\hline CASE: DI 8: & 235000 & CASE:122: & $-1 \$ 21^{\prime} \mathrm{J} 22+\mathrm{J} 22$ \\
\hline CASE :E 18: & +D18+E \$17*D18 & CASEU22: & 85000 \\
\hline CASE :F 18: & $-F \$ 17 * G 18+G 18$ & CASE :K22: & $+\mathrm{J} 22+K 32 \mathrm{VJ} 22$ \\
\hline CASE:G 18: & $+D 18+D 18^{\prime} 0,2$ & CASE :L22: & $\cdot 1521$ M22+M22 \\
\hline CASE:H18: & $+G 18+H \$ 17 * G 18$ & CASE:M22: & 103500 \\
\hline CASE :118: & $-1 \$ 17 *$ J $18+$ J 18 & CASE :N22: & $+\mathrm{M} 22+\mathrm{N} \$ 21 \mathrm{M} 22$ \\
\hline CASEJ 18: & $+G 18+G 18 * 0,16$ & CASE :022: & $-0 \$ 21 * P 22+P 22$ \\
\hline CASE 1K18: & +J 18+K\$17*J 18 & CASE :P22: & 118000 \\
\hline CASE :L18: & $-L \$ 17 * M 1 B+M 18$ & CASE:Q22: & $+P 22+Q \$ 21 * P 22$ \\
\hline CASE :M18: & $+\mathrm{J} 18+\mathrm{J} 18 * 0,12$ & CASE :B23: & 'Net Fiow \\
\hline CASEtNIS: & $+M 18+N \$ 17 * M 18$ & CASE:C23: & +C 18+C 20-E 22 \\
\hline CASEtoIS: & $-0 \$ 17 * \mathrm{P} 18+\mathrm{P} 18$ & CASE :D23: & +D18+D20-D22 \\
\hline CASE :P 18: & +M18+M18*0,08 & CASEE 23: & +E 18+E 20-C22 \\
\hline CASE :Q 18: & +P18+Q\$17*P18 & CASE :F23: & +F18+F20-H22 \\
\hline CASE:C19: & 0,08 & CASE :G23: & $+G 18+G 20-G 22$ \\
\hline CASE :E 19: & 0,03 & CASE:H23: & +H18+H20-F22 \\
\hline CASE:FI9: & 0,08 & CASE:123: & $+118+120-$ K22 \\
\hline CASE:H19: & 0,03 & CASEJ 23: & $+\mathrm{J} 18+\mathrm{J} 20-\mathrm{J} 22$ \\
\hline CASE-.II9: & 0,08 & CASE :K23: & $+K 18+K 20-122$ \\
\hline CASE :K19: & 0,03 & CASE :L23: & +L18+L20-N22 \\
\hline CASE:U9: & 0,08 & CASE :M23: & $+M 18+M 20-M 22$ \\
\hline CASE :NI9: & 0,03 & CASE :N23: & +N18+N20-L22 \\
\hline CASE:019: & 0,08 & CASE:023: & $+018+0204222$ \\
\hline CASE:Q I9: & 0,03 & CASE :P23: & +P18+P20-P22 \\
\hline CASE:B20: & 'Peppers & CASE:Q23: & $+Q 18+Q 20-022$ \\
\hline CASE:C20: & $-C S 19-D 20+D 20$ & CASE:B24: & 'Present Flow \\
\hline CASE :D20: & 44000 & CASE:C24: & $+C 23 / E 26$ \\
\hline CASE:E 20: & +D20+E \$19'D20 & CASE :D24: & +D23/D26 \\
\hline CASE :F 20: & $-F \$ 19 * G 20+G 20$ & CASE :E 24: & tE 23/C26 \\
\hline CASE:G20: & +D20+D20'0,15 & CASEF24: & +F23/H26 \\
\hline CASE:H20: & $+\mathrm{G} 20+H \$ 19 * G 20$ & CASE:G24: & $+G 23 / G 26$ \\
\hline CAS\&120: & $-|S|$ g*J 20+J 20 & CASE:H24: & +H23/F 26 \\
\hline CASEJ 20: & $+G 20+G 20 * 0,12$ & CASE :124: & $+123 / K 26$ \\
\hline CASE:K20: & +J 20+K\$19*J 20 & CASEJ 24: & $+\mathrm{J} 23 / \mathrm{J} 26$ \\
\hline CASE :L20: & -LS19*M20+M20 & CASE:K24: & $+K 23 / 126$ \\
\hline CASE :M20: & $+\mathrm{J} 20+\mathrm{J} 20 * 0,11$ & CASE :L24: & +L23/N26 \\
\hline
\end{tabular}




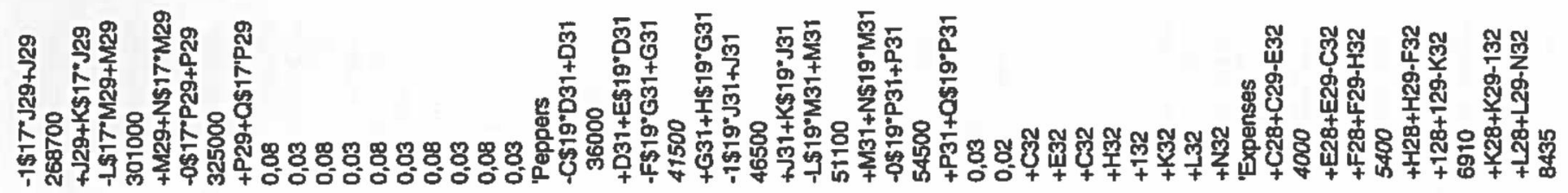

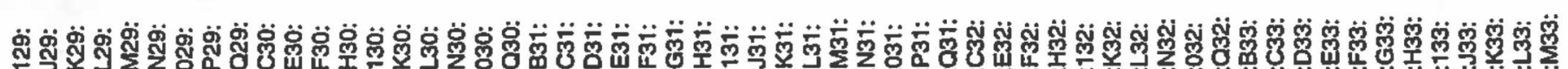

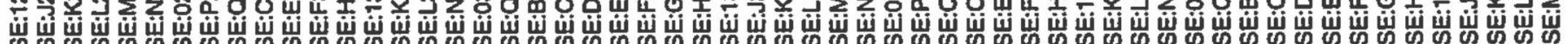

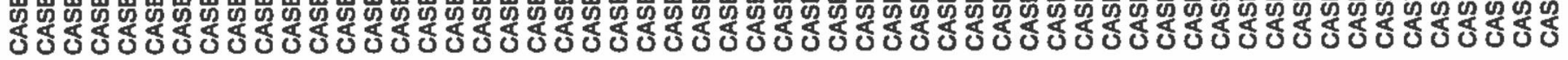

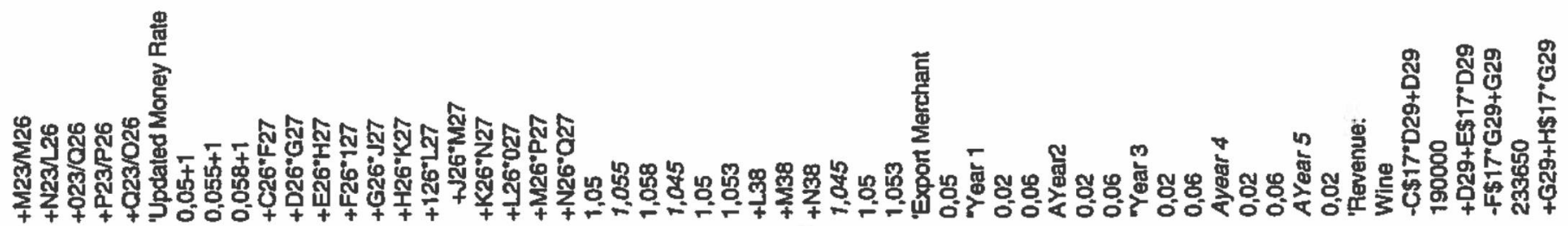

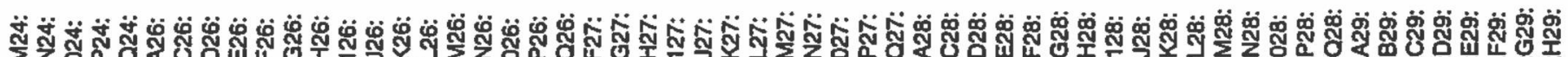

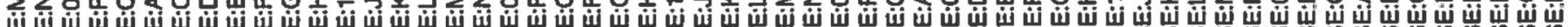

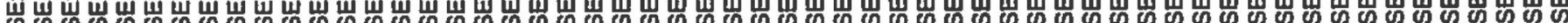

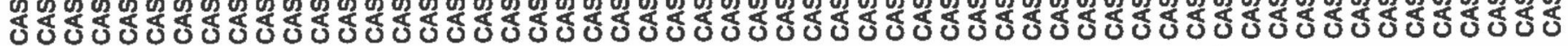




\begin{tabular}{|c|c|}
\hline CASE:N33: & +N28+N29-L32 \\
\hline CASE 1033: & $+028+029032$ \\
\hline CASE :P 33: & 9615 \\
\hline CASE:Q33: & $+Q 28+029-032$ \\
\hline CASE :B34: & Net Flow \\
\hline CASE :C 34: & $0 \$ 32 * D 34+D 34$ \\
\hline CASE 1D34: & +D29+D31-D33 \\
\hline CASE 1E 34: & +D34+E \$32*D34 \\
\hline CASE 1F34: & $-F \$ 32 * G 34+G 34$ \\
\hline CASE 1G 34: & +G 29+G 31-G 33 \\
\hline CASE 1H34: & +G 34+H\$32'G 34 \\
\hline CASE :134: & $-1 \$ 32$ J $34+\mathrm{J} 34$ \\
\hline CASEJ 34: & $+\mathrm{J} 29+\mathrm{J} 31-\mathrm{J} 33$ \\
\hline CASE :K34; & +J 34+KS32-J 34 \\
\hline CASE :L34: & -L\$32'M34+M34 \\
\hline CASE :M34: & $+M 29+M 31-M 33$ \\
\hline CASE :N34: & $+M 34+N \$ 32 * M 34$ \\
\hline CASE :034: & $-0 \$ 32 * \mathrm{P} 34+\mathrm{P} 34$ \\
\hline CASE:P34: & +P29+P31-P33 \\
\hline CASE:Q34: & +P34+Q\$32*P 34 \\
\hline CASE:B35: & 'Present Row \\
\hline CASE:C 35: & +C 34/E 37 \\
\hline CASE 1D35: & +D34/D37 \\
\hline CASE:E35: & $+E 34 / C 37$ \\
\hline CASE :F 35: & +F34/H37 \\
\hline CASE 1G 35: & +G 34/G 37 \\
\hline CASE 1H35: & +H34/F37 \\
\hline CAS Eli 35: & $-1 \$ 32 * \mathrm{~J} 35+\mathrm{J} 35$ \\
\hline CASEJ 35: & +J 34/J 37 \\
\hline CASE 1K35: & +J 35+K\$32*J 35 \\
\hline CASE :L35: & -L\$32'M35+M35 \\
\hline CASE :M35: & +M34/M37 \\
\hline CASE :N35: & +M35+N\$32*M35 \\
\hline CASE:035: & $-0 \$ 32 * P 35+P 35$ \\
\hline CASE 1P35: & +P34/P37 \\
\hline CASE 1Q35: & $+\mathrm{P} 35+0 \$ 32 * \mathrm{P} 35$ \\
\hline CASE 1A37: & 'Updated Money Rate \\
\hline CASE 1C 37: & $0,06+1$ \\
\hline CASE 1D37: & $0,065+1$ \\
\hline CASE 1E 37: & $0,068+1$ \\
\hline CASE :F37: & $+\mathrm{C} 37 * \mathrm{~F} 38$ \\
\hline CASE.G37: & +D37-G 38 \\
\hline CASE :H37: & +E 37*H38 \\
\hline CAS\&137: & +F37'138 \\
\hline CASEJ 37: & +G 37*J 38 \\
\hline CASE:K37: & +H37-K38 \\
\hline CASE :L37: & $+137 * L 38$ \\
\hline CASE:M37: & $+\mathrm{J} 37 * \mathrm{M} 38$ \\
\hline CASE :N37: & $+K 37 * N 38$ \\
\hline CASE :037: & $+137 * 038$ \\
\hline CASE :P37: & $+M 37 * P 38$ \\
\hline CASE:Q37: & +N3T038 \\
\hline CASE :F 38: & 1,07 \\
\hline CASE:G 38: & 1,075 \\
\hline CASE :H38: & 1,078 \\
\hline CASE:138: & 1,06 \\
\hline CASEj 38: & 1,063 \\
\hline
\end{tabular}

\begin{tabular}{|c|c|}
\hline CASE :K38: & 1,065 \\
\hline CASE:L38: & 1,048 \\
\hline CASE:M38: & 1,053 \\
\hline CASE:N38: & 1,056 \\
\hline CASE:038: & 1,055 \\
\hline CASE:P38: & 1,06 \\
\hline CASE :Q38: & 1,063 \\
\hline CASE 1A42: & ФET PRESENT VALUE \\
\hline CASE:A44: & +A6 \\
\hline CASE:C 44: & $+C 13+F 13+113+L 13+013$ \\
\hline CASE:D44: & +D13+G 13+J 13+M13+P13 \\
\hline CASE:E 44: & $+\mathrm{E} 13+\mathrm{H} 13+\mathrm{K} 13+\mathrm{N} 13+013$ \\
\hline CASE 1A45: & 'Centroid \\
\hline CASE:D45: & (+C 44+2*D44+E 44)14 \\
\hline CASE:A47: & +A17 \\
\hline CASE:C47: & +C24+F24+124+124+024 \\
\hline CASE:D47: & +D24+G 24+J 24+M24+P24 \\
\hline CASE:E 47: & +E 24+H24+K24+N24+Q24 \\
\hline CASE 1A48: & $+\mathbf{A 4 5}$ \\
\hline CASE 1D48: & $(+C 47+2 * D 47+E 47) 14$ \\
\hline CASE 1A50: & +A28 \\
\hline CASE:C50: & +C 35+F35+135+L35+035 \\
\hline CASE:D50: & +D35+G35+J 35+M35+P35 \\
\hline CASE:E 50: & $+\mathrm{E} 35+\mathrm{H} 35+\mathrm{K} 35+\mathrm{N} 35+\mathrm{Q} 35$ \\
\hline CASE:A51: & +A48 \\
\hline CAS\&D51: & $(+C S O+2 * D 50+E 50) 14$ \\
\hline
\end{tabular}

